\section{Cellular retention on diagnostic contact lenses: an evaluation of current cleaning protocol}

${ }^{1}$ Department of Opthalmology, Princess Alexandra Eye Pavilion, Chalmers Street, Edinburgh, UK

${ }^{2}$ University of Edinburgh, Teviot Place, Edinburgh, UK

Correspondence:

M MacRae,

Department of

Opthalmology,

Princess Alexandra

Eye Pavilion,

Chalmers Street, Edinburgh, Lothian EH3 9HA, UK Tel: + 441315361674 ; Fax: + 441315361574 E-mail: mary.macrae@ doctors.org.uk

Received: 17 November 2005

Accepted in revised form: 23 April 2006

Published online:

4 August 2006

\begin{abstract}
Aims To compare cellular contamination of diagnostic contact lenses after two different cleaning methods.

Methods Twenty-five used diagnostic contact lenses were cleaned by two different methods and the material retained on their contact surface examined for cells. Two diagnostic contact lenses were examined using electron microscopy and surface debris was subjected to $\mathrm{x}$-ray photoelectron spectroscopy.

Results Significantly more cells were present on used lenses compared with controls $(P<0.001)$. There was no significant difference in total cell count between the lenses subjected to the two cleaning strategies but the lenses simply wiped clean retained marginally more nucleated cells than controls $(P=0.039)$. Electron microscopy showed the majority of the debris on or close to the rim of the lens. X-ray photoelectron spectroscopy confirmed the presence of proteinaceous material. Conclusions Regardless of cleaning method, significant cellular debris is retained on the surface of diagnostic contact lenses after use. Eye (2007) 21, 1384-1386; doi:10.1038/sj.eye.6702450; published online 4 August 2006
\end{abstract}

Keywords: contact lens; prion protein; $\mathrm{X}$-ray photoelectron spectroscopy; decontamination

\section{Introduction}

Reusable ophthalmic instruments that touch the cornea such as tonometer heads and diagnostic contact lenses provide a potential route of propagation of abnormal prion protein in Creutzfeldt-Jacob Disease and Variant Creutzfeldt-Jacob Disease (CJD and vCJD). ${ }^{1}$ There is weak evidence of a link between tonometry and CJD. ${ }^{2,3}$ Previous studies have shown retention of cellular material on tonometer heads ${ }^{1}$ and $\mathrm{X}$-ray photoelectron spectroscopy (XPS) has been used to demonstrate adsorption of tear film components to the surface of soft and rigid gas permeable contact lenses. ${ }^{4}$ Although there is no evidence of transmission of CJD through the use of diagnostic contact lenses, the Medical Devices Agency (UK) recommend that all instruments which touch the eye during examination should be restricted to single patient use. ${ }^{5,6}$ This is prohibitively expensive for most UK eye departments so The Royal College of Ophthalmologists (UK) guidelines recommend risk management by careful cleaning and by assigning individual lenses to specific workstations in order to facilitate tracability. ${ }^{7}$ This study assesses the retention of corneal epithelial cells on diagnostic contact lenses after use and compares two cleaning methods. The results of XPS and scanning electron microscopy carried out on a used diagnostic contact lens are also presented.

\section{Materials and methods}

Diagnostic contact lenses (Volk Transequatorial and Area Centralis lenses) were randomised to one of two cleaning methods after use for the laser treatment of diabetic retinopathy. All eyes treated had been anaesthetised with topical benoxinate and a coupling gel had been applied.

Group $1(n=14)$ : lenses were wiped with a dry tissue. This reflects what may often happen in practice.

Group $2(n=11)$ : lenses were wiped with a tissue, soaked in sodium hypochlorite solution $0.05 \% \mathrm{w} / \mathrm{v}$ for $10 \mathrm{~min}$, rinsed in saline and dried with another tissue. This follows the Royal College of Ophthalmologists (UK) guidelines and the current departmental protocol. 
Material was removed from the contact surface of the lenses using adhesive tape and an impression made on a clean glass slide. The slides were fixed then stained with haematoxylin and eosin. All nucleated and nonnucleated cells within a mark showing the edge of the lens impression were counted by a single-blinded observer. Within clumps of cells, an estimate was made of the number present.

Control group $(n=10)$ : lenses were subjected to 20 applications of adhesive tape in order to remove all debris present, and then sampled as described above.

A Kruskal-Wallis nonparametric one way analysis of variance was used to compare the groups in terms of cells counted. The Mann-Whitney $U$-test was used to observe any specific differences between the groups and observe any effect of gender or type of lens used, but as the spread of data was too sparse for asymptotic $P$-values to be strictly accurate, two tailed Monte-Carlo $P$-values were calculated. This was done for both total cell counts and nucleated cell counts.

Two Goldmann three-mirror contact lenses removed from the outpatients clinic at the end of a day following cleansing and storage were examined with a scanning electron microscope then XPS of surface debris was carried out.

The study underwent an ethical assessment for a medical student 'Options' project at Edinburgh University. As the project did not involve any modification of investigation, treatment or other aspect

Table 1 Retained cells for each group

\begin{tabular}{lccc}
\hline Group & $\begin{array}{c}\text { Median total } \\
\text { cells (range) }\end{array}$ & $\begin{array}{c}\text { Median } \\
\text { nucleated cells } \\
\text { (range) }\end{array}$ & $\begin{array}{c}\text { Median non- } \\
\text { nucleated cells } \\
\text { (range) }\end{array}$ \\
\hline Group 1 $(n=14)$ & $5(1,37)$ & $0(0,5)$ & $5(1,26)$ \\
Group 2 $(n=11)$ & $4.5(1,28)$ & $0(0,10)$ & $4.5(0,27)$ \\
Control $(n=10)$ & $0(0,2)$ & 0 & $0(0,2)$ \\
\hline
\end{tabular}
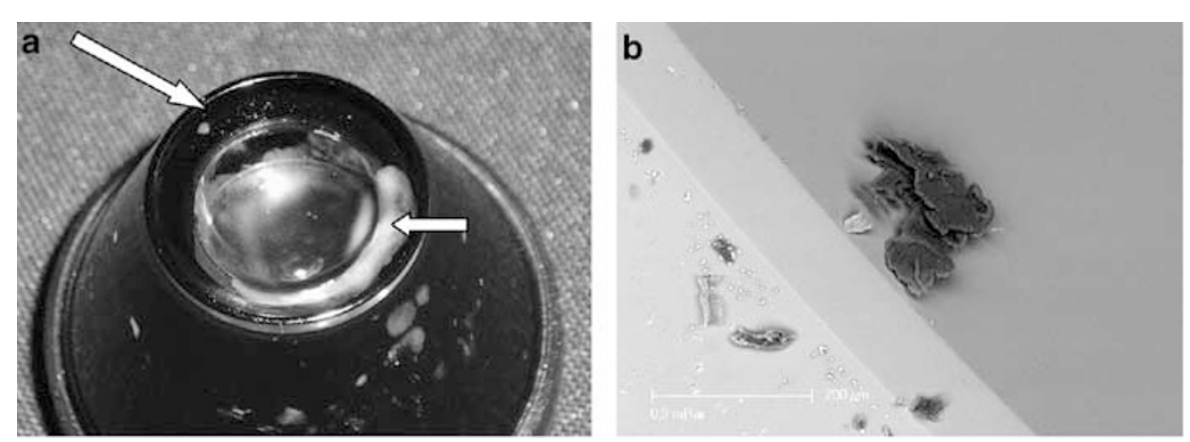

Figure 1 (a) Goldmann contact lens with damage to the surface (short arrow) and debris on the rim (long arrow). (b) Electron photomicrograph showing debris found close to rim of contact lens $\times 400$. of clinical practice and did not involve any potentially physically or mentally invasive procedures on volunteers no further ethical approval was considered necessary.

\section{Results}

There was no significant difference in total cell count between groups 1 and 2 (Table 1), however, both groups showed a higher total yield of cells than the control group ( $P<0.001$ for both). Group 1 showed marginally more nucleated cells than the control group $(P=0.039)$ while no difference was found between group 2 and the control group, or between groups 1 and 2. No significant differences were found between total and non-nucleated cell retention on the two different types of lenses used. No gender effect was identified.

Electron microscopy demonstrated debris on the surface of the Goldmann contact lenses (Figure 1). Most of the debris was on or close to the rim. XPS of the debris compared with clean lens demonstrated extra spikes for carbon, nitrogen, oxygen and sulphur, suggesting the presence of proteinaceous material which may originate from the tear film, or corneal surface (Figure 2). ${ }^{3}$

\section{Discussion}

These electron microscopy and XPS studies highlight the presence of proteinaceous material on a used diagnostic contact lens. The visualisation of cellular debris on used diagnostic contact lenses despite cleansing using standard protocols is of concern to the practicing ophthalmologist. The comparison of two different cleaning methods demonstrates that neither process successfully decontaminates used diagnostic contact lenses. The presence of marginally more nucleated cells on the lenses which were simply wiped clean is suggestive of increased contamination with corneal epithelial cells. The non-nucleated cells may have originated from the corneal surface ${ }^{8}$ or they may have 


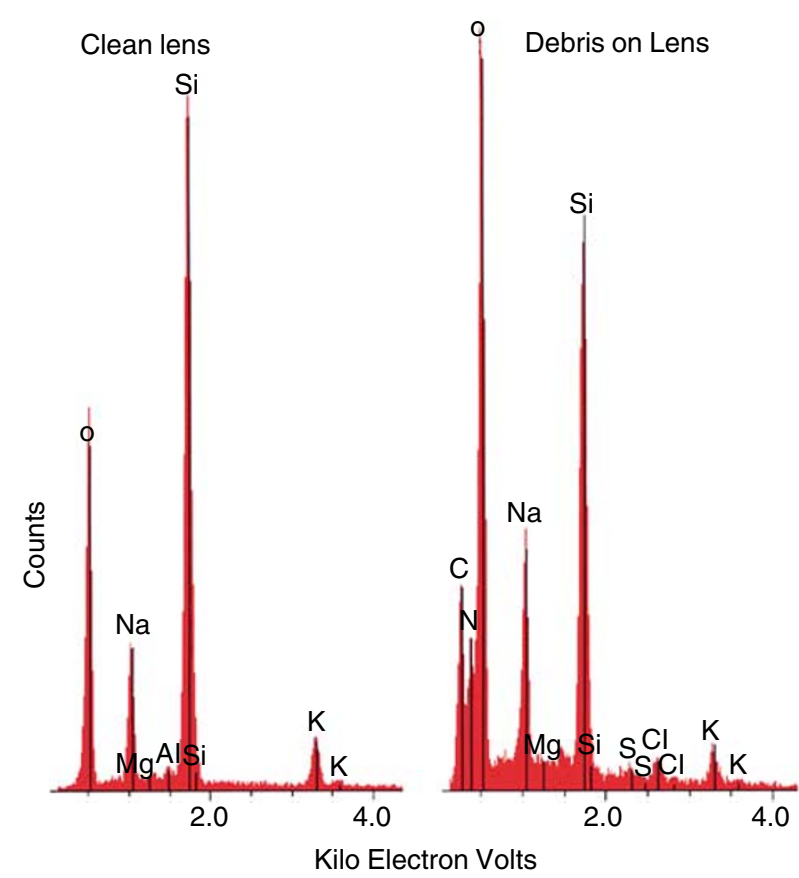

Figure 2 X-ray photoelectron spectroscopy report for clean lens (left) and used contact lens (right).

been shed from the lid margin or the practitioner's hands. One might have expected an increased level of contamination of the transequatorial lens when compared with the area centralis lens since pan-retinal photocoagulation generally takes longer than macular photocoagulation and often requires more manipulation and rotation of the lens on the cornea. This was not however the case. While the presence of coupling fluid may reduce the risk of debris transfer, it may be appropriate to use disposable covers for lenses ('Sterycup', Haag-Streit) in 'at risk' patient groups. This may, however, reduce the optical clarity for laser treatment delivery and alter spot size on the retina.
Further work is required to examine factors, which determine increased corneal epithelial shed rate and to determine whether the addition of a mechanical cleaning step (e.g. rubbing the lens under running water especially around the lens rim) would enhance the efficacy of the cleaning procedure.

\section{Acknowledgements}

The authors thank Helen Baxter for carrying out the x-ray photoelectron spectroscopy, Marion Brannon and Stuart Gairns for their assistance with images and graphics and Dave Signorini for statistical advice.

\section{References}

1 Lim R, Dhillon B, Kurian KM, Aspinall PA, Fernie K, Ironside JW. Retention of corneal epithelial cells following Goldmann tonometry: implications for CJD risk. Br J Ophthalmol 2003; 87: 583-586.

2 Davanipour Z, Alter M, Sobel E, Asher D, Gajdusek DC. Creutzfeldt-Jakob disease: possible medical risk factors. Neurology 1985; 35: 1483-1486.

3 Mehtra JS, Osborne RJ, Bloom PA. Varient CJD and tonometry. Br J Opthalmol 2004; 88: 597-598.

4 McArthur SL, McLean KM, St John HAW, Greisser H. XPS and surface-MALDI-MS characterization of worn HEMAbased contact lenses. Biomaterials 2001; 22: 3295-3304.

5 MDA AN1999(03). Single patient use of contact lenses: implications for clinical practice. Medical Devices Agency, October 1999. www.mhra.gov.uk.

6 MDA AN1999(04). Single patient use of ophthalmic medical devices: implications for clinical practice. Medical Devices Agency, October 1999. www.mhra.gov.uk.

7 Creutzfeldt-Jakob Disease (CJD) and Ophthalmology. Royal College of Ophthalmologists guidelines, December 2003. www.rcophth.ac.uk.

8 Zhou J, Begely C, Wright A, Wilson G, Tokarski T. Characterisation of cells collected from the normal human ocular surface by contact lens cytology. Cornea 2000; 19(6): 824-832. 